\title{
BMJ Open Does the performance of five back- associated exercises relate to the presence of low back pain? A cross- sectional observational investigation in regional Australian council workers
}

\author{
Charles Philip Gabel, ${ }^{1}$ Hamid Reza Mokhtarinia, ${ }^{2}$ Jonathan Hoffman, ${ }^{3}$ \\ Jason Osborne, ${ }^{4,5}$ E-Liisa Laakso, ${ }^{6,7}$ Markus Melloh ${ }^{8,9,10}$
}

To cite: Gabel $\mathrm{CP}$

Mokhtarinia HR, Hoffman J, et al. Does the performance of five back-associated exercises relate to the presence of low back pain? A cross-sectional observational investigation in regional Australian council workers. BMJ Open 2018;8:e20946. doi:10.1136/ bmjopen-2017-020946

- Prepublication history for this paper is available online. To view these files, please visit the journal online (http://dx.doi. org/10.1136/bmjopen-2017020946).

Received 13 December 2017 Revised 29 May 2018 Accepted 18 June 2018

Check for updates

(c) Author(s) (or their employer(s)) 2018. Re-use permitted under CC BY-NC. No commercial re-use. See rights and permissions. Published by BMJ.

For numbered affiliations see end of article.

Correspondence to Dr Charles Philip Gabel; cp.gabel@bigpond.com

\section{ABSTRACT}

Objectives Investigate the relationships between the ability/inability to perform five physical test exercises and the presence or absence of low back pain (LBP).

Setting Regional Australian council training facility. Participants Consecutive participants recruited during 39 back education classes (8-26 participants per class) for workers in general office/administration, parks/gardens maintenance, roads maintenance, library, child care and management. Total sample $(n=539)$ was reduced through non-consent and insufficient demographic data to $n=422$. Age $38.6 \pm 15.3$ years, range $18-64$ years, $67.1 \%$ male. Methods Cross-sectional, exploratory, observational investigation. LBP presence was ascertained from a three-response option questionnaire: $0=$ none/rarely (no) $1=$ sometimes (some), 2=mostly/always (most). Statistical correlation was performed with the number of the five test exercises the individual successfully performed: (1) extension in lying: $3 \mathrm{~s}$; (2) 'toilet squat'; feet flat, feet touched: $3 \mathrm{~s}$; (3) full squat then stand up: 5 times; (4) supine sit-up, knees flexed: 10 times; and (5) leg extension, supine bilateral: 10 times.

Interventions Nil.

Results For the group 'no-some', 94.3\% completed 4-5 test exercises, while for group 'With', 95.7\% completed 0-1 test exercises. The relationship between LBP presence and number of exercises performed was highly significant $\left(\chi_{(10)}^{2}=300.61, p<0.001\right)$. Furthermore, multinomial logistic regression predicting $\operatorname{LBP}(0=\mathrm{no}, 1=$ some, $2=$ most) from the number of exercises completed, substantially improved the model fit (initial-2LL=348.246, final-2LL=73.620, $\left.\chi_{(2)}^{2}=274.626, p<0.001\right)$. As the number of exercises performed increased, the odds of reporting 'some LBP' or 'most LBP' dropped substantially (ORs of 0.34 and 0.17 , respectively).

Conclusion The ability to complete/not complete five test exercises correlated statistically and significantly with a higher LBP absence/presence in a general working population. Training individuals to complete such exercises could facilitate reductions in LBP incidence; however, causality cannot be inferred. Randomised trials are recommended to establish the potential efficacy of exercise-based approaches, considering these five selected exercises, for predicting and managing LBP.
Strengths and limitations of this study

- The sample diversity with continuity and subsequent homogeneity enabled generalisation to be inferred.

- This was a cross-sectional, exploratory, observational investigation.

- It is representative of a general working population as it contained diverse occupations, ages, both genders and a consecutive sample from regional council workers during an educational workshop.

- The sample size was sufficient to ensure adequate power.

- The functional exercises were not tailored for either dose or specificity for age or gender.

\section{INTRODUCTION}

Low back pain (LBP) is among the world's most prevalent occupational disorders in working populations ${ }^{1}$ and major global public health concerns ${ }^{2}{ }^{3}$ and worsening due to increasing age and populations. ${ }^{4}$ It affects $12 \%$ of the world's population at any given time $^{25}$ with lifetime prevalence at $84 \%$ and chronicity around $23 \% .^{2}$ When disability-adjusted life years are considered, LBP is a leading global cause of disease burden. ${ }^{56}$ LBP is distinctive in that limited progress has occurred in identifying effective prevention strategies and treatments ${ }^{78}$ and remains nearly impossible to provide absolute certainty of a specific nociceptive cause, and only a small proportion has a recognised pathological cause. ${ }^{36}$ This is despite established recognition and identification of factors that predispose or correlate to future LBP. $^{6} 910$ Predicting problematic LBP has several promising protocols including questionnaire-based biopsychosocial screening methods $^{11-13}$ and movement patterns or maladaptive postures. ${ }^{14}$ There are, however, 
few or no validated physiological or physical predictive screening tests ${ }^{15}$ including measures of disuse or changed levels of physical conditioning. ${ }^{16}$

The LBP economic burden leads to reduced efficiency and productivity by individuals, organisations and the community compounding direct or indirect costs to private, professional and governmental medical care stakeholders, wages compensation, worker recruitment and training and productivity losses. ${ }^{517}$ These factors are further inflated by social consequences to individuals, families, communities and general society. ${ }^{18} 19$ Despite many recognised risk factors that predispose individuals to LBP, ${ }^{10}{ }^{20}$ business process trends in work settings coupled with recent technology advancement have seen occupational and social changes that influence the requirements or personal choices to adopt static postures. ${ }^{21}$ In contrast, manual workers have gained both advantages and disadvantages, with occupational postures and loads in areas such as maintenance and building having remained consistent. ${ }^{1422}$

The direction of contemporary research on LBP prevention and recurrence has focused on non-modifiable factors and long-term exposures. These include: medical investigative relationships such as radiological ${ }^{2324}$ or physiological findings ${ }^{25-27}$ that have produced mixed results even from the same study ${ }^{28}$ and biopsychosocial considerations ${ }^{29-32}$ or a mixture of these. ${ }^{9-11}$ In contrast, modifiable factors ${ }^{33} 34$ including movement patterns, ${ }^{14}{ }^{35}$ physiological loads ${ }^{36}$ and exercise capacity ${ }^{3738}$ receive limited attention yet they significantly influence LBP morbidity and symptomology, ${ }^{12}$ being recognised as potentially able to prevent LBP. $^{1120}$

LBP disorders are multifactorial with individual symptomology influenced by various pathoanatomical, physical, neurophysiological, psychological and social contributors. ${ }^{31436}$ Consequently, voluntary activities that involve lumbopelvic-specific exercises are effective in primary and secondary LBP prevention. ${ }^{39}$ Such exercises improve fitness and occupational status by diminishing disability and problem severity ${ }^{35} 40$ and may counter selective atrophy of type II fibres found in the presence of pathological changes. ${ }^{4142}$ However, muscle recruitment remains predominantly neural based during rehabilitation with psychological adaptations derived from improved motivation and pain tolerance. ${ }^{43}$ The conundrum remains that LBP reduces functional capacity, fitness and general health status (GHS), including depression, ${ }^{44}$ while low capacity from pathology, injury, GHS or sedentary lifestyle increases the risk of LBP. ${ }^{45}$ The need to consider modifiable factors is supported by recent research ${ }^{46}$ that confirmed the relationship between dynamic physical tests, self-reported LBP and reduced function. ${ }^{38} 47$

Existing research has a knowledge gap for modifiable factors demonstrating a need for observational studies in representative working populations. ${ }^{3611}$ Addressing this gap will assist in identifying the relationship between LBP symptoms and individual physical functional movement capabilities. A representative group, with strong indicators of generalisability, is council workers. The group includes diversity of gender, age and occupations with variance in manual and sustained loads ${ }^{48}$ and stationary and sedentary postures. ${ }^{49}$ Cross-sectional analysis of these groups is a starting point in implied generalisation and provides insight into the capacities and abilities that may lead to the presence or risk of LBP. ${ }^{50} 51$

This observational study investigated council workers, as an implied representative general working population sample and evaluated whether the ability, or not, to perform five back-related exercises could determine or predict the presence or absence of LBP. We hypothesised that the test exercises would demonstrate the ability of the lumbar spine to: move in a controlled manner through normal range as a complex multisegmental functional activity with coordinated biomechanical and neuromuscular components and be stabilised, as part of the lumbo-pelvic-hip complex, through motor control of the integrated muscular system. ${ }^{36} 52$ Consequently, the ability to perform the exercises would correlate with lower self-reported LBP.

Once established, analysis of the findings might indicate what movements, or lack thereof, might be associated with the presence and/or absence of LBP for individuals in different occupational and physical activity settings. The outcomes might contribute to understanding the relevance of functional movement and exercises in relation to LBP and provide a direction for future prospective studies. Such studies could identify specific functional movements for specific tasks or risk groups, then provide structured exercise regimens that might reduce LBP and its predisposition.

\section{METHODS}

A cross-sectional, exploratory, observational investigation was initiated over a period of 28 months in a population of employees with the Sunshine Coast Regional Council in Queensland, Australia. Workers from a convenience sample were consecutively recruited during 39 annual back educational programme classes of 2-hours duration. The first two classes provided a pilot study $(n=33)$ to estimate effect size, and 'Bootstrap analysis' ensured the effect size had reasonable confidence. Standard power estimation calculations on the range of anticipated effect sizes provided minimum sample size goals. The participants were recruited from a range of occupations, ages and work locations to provide participants that reasonably reflected the population of interest. This representative population minimised selection bias; however, potential bias remained from non-response, the volunteer consent requirement and ascertainment bias. Most participants were classified in to 21 occupational categories with an additional 'Other' category for miscellaneous non-specified occupations. Class participant numbers ranged from 8 to 26 , with a total sample of $n=539$. Only participants who consented were included. Data were excluded if there was insufficient demographic information. Consequently, 


\begin{tabular}{|c|c|c|c|c|c|}
\hline Occupation (job) & Total & $\%$ Total & Male & $\%$ Total & $\%$ Male \\
\hline Age (years) & $38.6 \pm 15.3$ & \multicolumn{4}{|c|}{ Range: 18-64 } \\
\hline Archives & 10 & 2.4 & 4 & 0.9 & 40.0 \\
\hline Airport maintenance & 3 & 0.7 & 3 & 0.7 & $100.0^{*}$ \\
\hline Child care & 36 & 8.5 & 3 & 0.7 & $7.5 \dagger$ \\
\hline Community services & 34 & 8.1 & 1 & 0.2 & $3.3 \dagger$ \\
\hline Construction & 22 & 5.2 & 22 & 5.2 & $100.0^{*}$ \\
\hline Corporate records & 7 & 1.7 & 2 & 0.5 & $28.6 \dagger$ \\
\hline Emergency room & 21 & 5.0 & 15 & 3.6 & $71.4^{\star}$ \\
\hline Fleet and plant & 16 & 3.8 & 16 & 3.8 & 100.0 \\
\hline Information systems & 5 & 1.2 & 2 & 0.5 & 40.0 \\
\hline Information technology & 11 & 2.6 & 9 & 2.1 & $81.8^{*}$ \\
\hline Infrastructure & 12 & 2.8 & 8 & 1.9 & 66.7 \\
\hline Library & 46 & 10.9 & 15 & 3.6 & $32.6 \dagger$ \\
\hline National parks & 13 & 3.1 & 12 & 2.8 & $92.3^{*}$ \\
\hline Operations maintenance & 7 & 1.7 & 6 & 1.4 & $85.7^{*}$ \\
\hline Operations management & 11 & 2.6 & 7 & 1.7 & 63.6 \\
\hline Parks bushland services & 69 & 16.4 & 68 & 16.1 & $98.6^{*}$ \\
\hline People and organisational & 1 & 0.2 & 0 & 0.0 & $0.0 \dagger$ \\
\hline Roads management & 65 & 15.4 & 64 & 15.2 & $98.5^{\star}$ \\
\hline Strategy and planning & 11 & 2.6 & 7 & 1.7 & 63.6 \\
\hline Treasury and risk & 2 & 0.5 & 2 & 0.5 & $100.0^{*}$ \\
\hline Water services & 18 & 4.3 & 17 & 4.0 & $94.4^{*}$ \\
\hline Other & 2 & 0.5 & 0 & 0.0 & $0.0 \dagger$ \\
\hline Total & $\mathrm{n}=422$ & 100.0 & Male $=$ & Male $=67$ & \\
\hline
\end{tabular}

*Indicates male $>67 \%$.

†Indicates female $>67 \%$.

the sample was reduced to a total of $n=422$, age $38.6 \pm 15.3$ years, range 18-64 years, $67.3 \%$ male (see table 1 ). Males were predominant in manual occupational roles including maintenance and construction, while females were predominant in carer and resource management including child care, community services, library services and records roles.

\section{Test activities}

The test exercises were selected based on having significant elements of lumbo-pelvic-hip function and being recognised for reducing symptomology or risk of LBP. The five selected exercises were chosen to represent a balanced variation of functions required for normal daily activities. ${ }^{35}$ Three exercises previously investigated, 'repeated sit-ups', 'repeated squats' and 'extension in lying' (EIL), ${ }^{38}$ showed a positive correlation with LBP prevention and were consequently included. The sustained squat and leg extension exercises, respectively, require functional movement ${ }^{3652}$ and a predominantly isometric abdominal coactivation, ${ }^{53}$ which occur or simulate daily occupational and sports activities. ${ }^{54}$ Other exercises were considered but excluded, such as active spine flexion, which has shown poor correlation with LBP. $^{55}$

All participants were volunteers and performed five functional movement exercises during an educational session with other attendees, supervised by the session leader, a sports physiotherapist certified in McKenzie Manual Diagnostic Therapy. The instructions for exercise justification, instructions, completion and reliability are detailed in table 2. Intraobserver reliability for screening tests movement instruction is recognised as being moderate to high. ${ }^{56}$

\section{Questionnaire}

During the educational sessions each participant completed a self-report questionnaire: 'How often do you have low back pain?' with three response options: 'rarely/none', 'sometimes' or 'always/mostly', with the time frame and symptoms interpreted within their life context. This three-point scale is condensed from the WHO's five points: 'never', 'rarely', 'sometimes', 'often' and 'very often'. ${ }^{57}$ The central three-point response provides an 'intermediate' option, which is critical from 


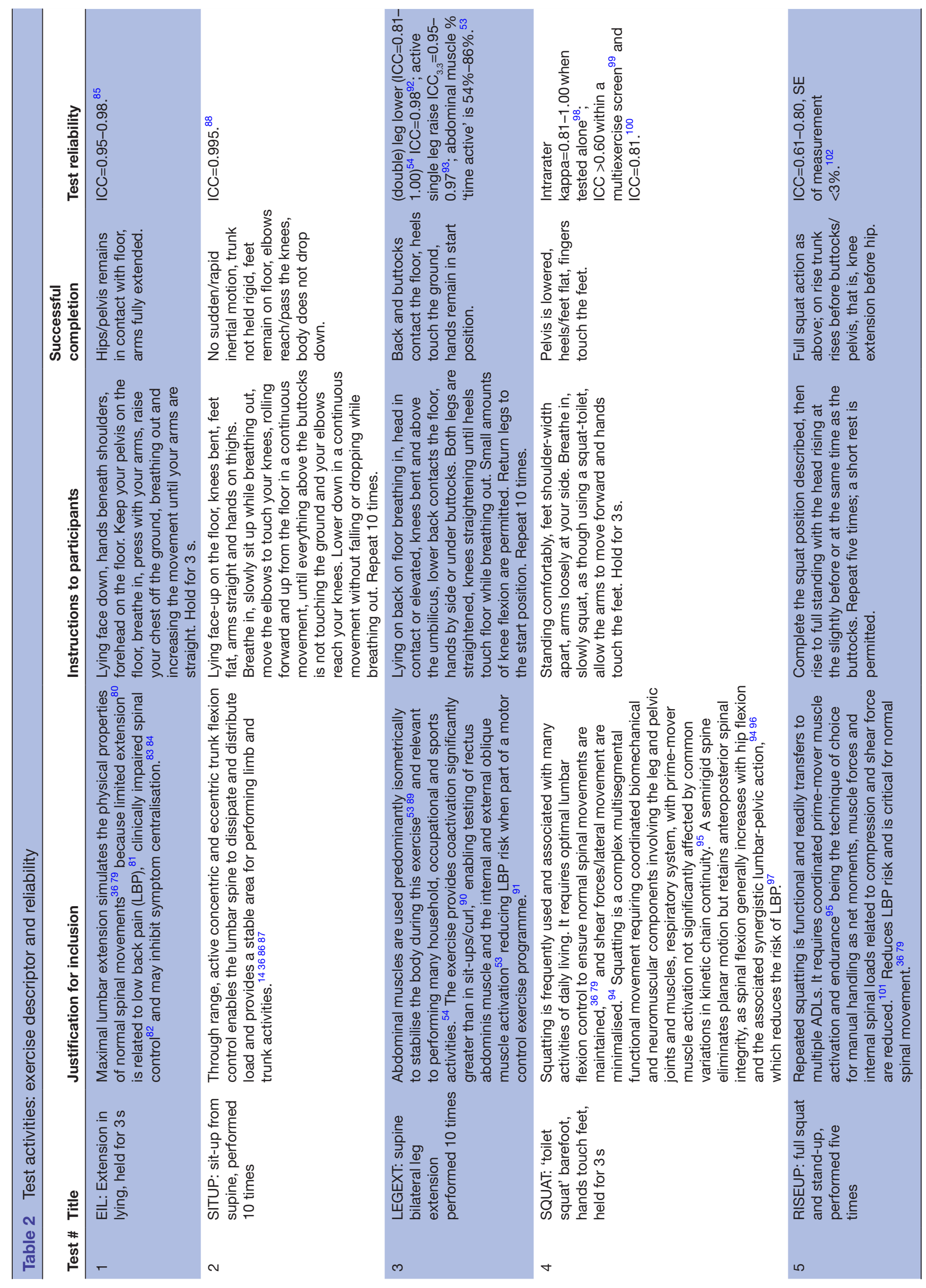


psychological and statistical perspectives. Psychologically, three cognitive perspectives facilitate response accuracy by reducing cognitive load ${ }^{58}{ }^{59}$ which improves precision and consistency. ${ }^{60}$ Statistically, responses were coded on a $0-1-2$ scale $^{6162}$ : $0=$ rarely/none (no LBP), $1=$ sometimes (some LBP) and 2=always/mostly (most LBP).

Statistical analysis was performed using SPSS V.23.0 for Windows with significance set at $\mathrm{p}<0.05$. Following preliminary data screening to ensure data quality (eg, no aberrant values), an initial cross-tabulation of LBP $(0=$ none, $1=$ some, $2=$ most $)$ and number of exercises was performed to explore whether self-reported LBP was related to the number of exercises completed. A $\chi^{2}$ test evaluated whether the null hypothesis (that the number of exercises completed would be consistent across LBP groups) was tenable or able to be rejected. Standard power calculations on the effect sizes verified that the minimum sample size was exceeded.

A multinomial logistic regression was performed, exploring whether the number of exercises (EX_SUM) predicted LBP (categorised as 0,1 and 2) to test the null hypothesis that the probability or odds of being classified into LBP groups are not different because of number of exercises performed and, if rejected, to quantify the change in odds or probability of LBP as it relates to number of exercises performed. This test also allowed us to evaluate whether participant gender interacted with EX_SUM, or whether there were non-linear effects present. Regression diagnostics for this analysis (eg, residuals and influence) were examined to ensure no aberrant cases were inappropriately influencing the analysis. ${ }^{63}$ None were identified.

Finally, if the null hypothesis from the prior multinomial logistic regression was rejected, we performed a second multinomial logistic regression on LBP entering each exercise as a predictor (rather than simply the count of number of exercises completed) to examine whether all exercises were uniquely predictive or whether some subset of exercises were more predictive than others. All five exercises were entered simultaneously, allowing for examination of unique effects of each variable controlling for all other variables in the equation. Regression diagnostics were examined, and no aberrant cases were identified. ${ }^{63}$

\section{Patient and public involvement}

The research question and outcome measures were developed over a 3-year period during delivery of a work site back care education programme to a regional council in Queensland, Australia. This involved both formal and informal work-related discussions with attendees and management enabling the programme and exercise selection to be progressively modified. This procedure informed programme progression, specifically the exercises and their relation to the presence or not of LBP, and ensured the priorities of exercise simplicity for the identification and prevention of LBP. The experience gained by this process refined the programme and the selected preferences guiding the statistical relation between the exercises and the presence or not of LBP. The results of each session were disseminated immediately to each participant, and after the initial 3 years of the programme and pilot statistical analysis, the statistical relation was discussed with the council management as part of the programme feedback.

\section{RESULTS}

For descriptive purposes, a cross-tabulation of LBP $(0=$ none, $1=$ some, $2=$ most $)$ and the number of exercises accomplished is presented in table 3. Most participants reporting no LBP could complete most exercises. For individuals with no LBP, $85.5 \%$ could complete at least four exercises. Exercise completion dropped significantly for participants with 'some' LBP. In this group, only $22.9 \%$ were able to complete four or more exercises, and for participants with 'most' LBP, only $10.5 \%$ were able to complete four or more exercises. Analysing participants in each category who failed to complete more than one exercise, the pattern is reversed. Only $2.9 \%$ of those with no LBP had trouble completing more than one exercise, while $23.7 \%$ of those with 'some LBP' and $74.3 \%$ of those with 'most LBP' were unable to complete more than one. A Pearson $\chi^{2}$ test was performed demonstrating a significant relationship between the variables of 'LBP' and 'number of exercises performed' $\left(X^{2}{ }_{(10)}=300.61\right.$, $\mathrm{p}<0.001)$.

A multinomial logistic regression predicting LBP $(0$, 1,2 , with 0 being the reference group) from the count of exercises that could be completed (EX_SUM, ranging from 0 to 5), showed a strong effect (initial-2LL=348.246, final-2LL=73.620, $\mathrm{X}_{(2)}^{2}=274.626$, $\mathrm{p}<0.001$; table 4 ).

As presented in table 5, as EX_SUM increased incrementally, the odds of reporting some LBP or most LBP reduced substantially: $\mathrm{OR}=0.34$ (95\% CI 0.27 to 0.44$)$ and 0.17 (95\% CI 0.12 to 0.23 ), for $\mathrm{LBP}=1$ and 2 , respectively. No curvilinear effect was present nor any gender effect.

A second multinomial logistic regression with the five exercise variables entered individually, rather than entering the total number accomplished, evaluated whether tests were individually predictive of LBP. As shown in table 6 , overall, the effect was similarly strong ${ }^{63}$ (initial-2LL=429.93, final-2LL=147.40, $\quad \mathrm{X}_{(2)}^{2}=282.53$, $\mathrm{p}<0.001$ ).

As table 7 presents, most exercises were individually predictive of LBP (when LBP=1, EIL was not uniquely predictive with all other variables in the equation). All others were statistically significant $(\mathrm{p}<0.002)$ with ORs ranging in magnitude from 0.21 to 0.38 . For 'Most' LBP $(\mathrm{LBP}=2)$, all exercises were significant independent predictors of LBP (all $\mathrm{p}<0.017$ ), with ORs ranging from 0.09 to 0.35 .

Sensitivity for the first analysis (per cent of participants with LBP correctly classified into LBP category) was $82.3 \%$, and specificity (percent of participants with no LBP classified as such) was $85.6 \%$. The positive predictive 
Table 3 Exercises accomplished as a function of LBP

\begin{tabular}{|c|c|c|c|c|c|}
\hline \multirow{2}{*}{\multicolumn{2}{|c|}{ Number of exercises completed }} & \multicolumn{3}{|l|}{ LBP } & \multirow[b]{2}{*}{ Total } \\
\hline & & \multirow{2}{*}{$\begin{array}{l}0 \\
\text { None } \\
1\end{array}$} & \multirow{2}{*}{$\begin{array}{l}1 \\
\text { Some } \\
8\end{array}$} & \multirow{2}{*}{\begin{tabular}{l|}
2 \\
Most \\
33
\end{tabular}} & \\
\hline 0 & Count & & & & 42 \\
\hline & $\%$ within LBP & 0.6 & 5.6 & 31.4 & 10.0 \\
\hline \multirow[t]{2}{*}{1} & Count & 4 & 26 & 45 & 75 \\
\hline & $\%$ within LBP & 2.3 & 18.1 & 42.9 & 17.8 \\
\hline \multirow[t]{2}{*}{2} & Count & 5 & 32 & 12 & 49 \\
\hline & $\%$ within LBP & 2.9 & 22.2 & 11.4 & 11.6 \\
\hline \multirow[t]{2}{*}{3} & Count & 15 & 45 & 4 & 64 \\
\hline & $\%$ within LBP & 8.7 & 31.3 & 3.8 & 15.2 \\
\hline \multirow[t]{2}{*}{4} & Count & 58 & 20 & 6 & 84 \\
\hline & $\%$ within LBP & 33.5 & 13.9 & 5.7 & 19.9 \\
\hline \multirow[t]{2}{*}{5} & Count & 90 & 13 & 5 & 108 \\
\hline & $\%$ within LBP & 52.0 & 9.0 & 4.8 & 25.6 \\
\hline \multirow[t]{2}{*}{ Total } & Count & 173 & 144 & 105 & 422 \\
\hline & $\%$ within LBP & 100.0 & 100.0 & 100.0 & 100.0 \\
\hline
\end{tabular}

LBP, low back pain.

value (true positives divided by true and false positives) was $89.1 \%$, and negative predictive value (true negatives divided by true and false negatives) was $77.1 \%$. Sensitivity for the second analysis was $79.5 \%$, and specificity was $87.9 \%$. Positive predictive value was $90.4 \%$, and negative predictive value was $74.9 \%$.

We also took into consideration a simple analysis relating the presence or absence of LBP to exercises. This approach, combining two groups of LBP (some and mostly) into one category potentially reduces the goodness of the analysis by combining two different groups into one heterogeneous group. If the two groups were distinct, this would increase error variance and decrease the power and informativeness of the analyses. Ancillary binary logistic regression analyses therefore tested the null hypothesis that the two LBP groups were similar. Results of this analysis, which predicted LBP (ie, some vs mostly) showed that EX_SUM was significantly related to this outcome (initial-2LL=339.05, final-2LL $=284.96$, $\left.\mathrm{X}^{2}{ }_{(1)}=54.09, \mathrm{p}<0.001\right)$, leading us to reject the null hypothesis and assert that these two groups are significantly distinct.

\section{DISCUSSION}

Previous research demonstrated a relationship between dynamic physical tests, self-reported LBP and reduced function. ${ }^{38}$ However, such research has been neglected in recent decades ${ }^{29-32}$ as focus shifted towards physiological and radiological findings ${ }^{910}$ and biopsychosocial attributes. ${ }^{36711}$ Grönblad $e t a l^{8}$ showed three physical exercises (repetitive sit-ups, squats and EIL) had a positive correlation with LBP. Our current study builds on this research as it expands the number of test exercises. It also shows a higher statistical correlation between physical exercise tests and LBP than found previously. These findings with robust effect sizes, and the $95 \%$ CIs, ${ }^{63}$ demonstrate a substantial relationship. Our results indicate that for each increase in the exercise number accomplished, the odds of having some LBP were about one-third less than that of those participants accomplishing one fewer exercise. The authors feel these research findings are generalisable to settings other than those originally tested due to several factors. The council worker population included 21 distinct occupational categories across manual and sedentary requirements under sustained and moveable loads, ${ }^{48}$ field work in both outdoor and

Table 4 Model summary entering only count of exercises completed (EX_SUM)

\section{Model fitting information}

\begin{tabular}{lllll}
\hline & Model fitting criteria & Likelihood ratio tests & & Sig. \\
\cline { 2 - 5 } Model & $\mathbf{- 2}$ log likelihood & $\chi^{2}$ & df & \\
\hline Intercept only & 348.246 & 274.626 & 2 & 0.000 \\
Final & 73.620 & 2700 \\
\hline
\end{tabular}


${ }^{*}$ The reference category is: 0 none.

LBP, low back pain.

indoor settings and included a broad distribution of age groups and both genders that indicate the abilities and capacities of workers that present some of the highest potential risk of $\mathrm{LBP}^{50}{ }^{51}$

This study clearly showed that the presence of LBP is significantly statistically related to the ability to perform the chosen exercise tasks. All exercises were uniquely predictive of LBP (except EIL where LBP=1). The total number of exercises completed was strongly related to LBP. The relevance of a gender effect and potential curvilinear effects was tested as per the accepted recommendation ${ }^{63}$ and found to have no effect on the results. Effectively, those able to perform more exercises were substantially less likely to report LBP. Consequently, these exercises have the potential to be a part of the areas of recommended necessary investigation in future research $^{311}$ in terms of the ability to provide a clinical diagnosis related to the potential or risk that an individual may develop LBP and perhaps even future impairment.

The ability to perform repeated squatting has been demonstrated to be inversely related to LBP as the balance between hip and lumbar spine mobility must be met, that is, better squatting ability is associated with reduced LBP. ${ }^{47}$ These researchers found females more susceptible to LBP if they had lower physical performance capacity, a finding not evident in our study. Furthermore, excess/prolonged squatting has a negative effect through increased LBP. ${ }^{64}$ Similarly, EIL is beneficial and facilitates lumbar lordosis maintenance. ${ }^{65}$ There is a direct link between a reduced lordosis and LBP. ${ }^{66}$ Lordosis maintenance is essential for disc symptomology centralisation for LBP management and preventative exercise strategies. ${ }^{65} 67$ The exercise alone was not predictive of LBP.

Back endurance testing is a statistically accurate LBP screening test as poor performance in static back endurance correlates to higher incidence. ${ }^{68} 69$ However, EIL is a passive test using the arms as the prime mover. It is possible that individuals with excessive lumbar extensor activation and substitution during this test may confound the results. Furthermore, some studies have indicated that trunk muscle strength measures in isolation are unrelated to LBP symptoms and functional ability.

Exercise therapy is an efficient, cost-effective LBP management strategy, ${ }^{71}$ but there is no evidence to support any single exercise. Coordinated muscle activity around the lumbopelvic region is considered vital for mechanical spinal stability. ${ }^{36} 72$ Several rehabilitative 'stabilisation exercise' approaches emphasise retraining functional movement patterns, rather than focusing on specific muscles. ${ }^{35} 73$ The tests we chose activate and challenge the global muscles of the abdomen and trunk, the 'abdominal brace' mechanism ${ }^{75}$ and their ability to act and interact in a synergistic and functional manner. We screened functional test performance where the aim was assessing participants' functional status regardless or not of LBP and its known or potential cause. As LBP increases in industrial societies with no clear cause, it is important to consider risk factors of physical workload and awkward posture $^{7}$ as well as preventative strategies that may play a key role in reducing healthcare system demands and societal support. The exercise tests we used primarily address abdominal and lumbopelvic muscles and their coordination with lower limb muscle activity and maintenance of balance. This coordination was recently defined as 'integral' in understanding lumbar stability as a complex integrated model. ${ }^{36}$ Personal efficiency in physical self-test completion can act as a screening methodology for individuals at risk of LBP. It is, however, important that the method of test performance is considered, for example, there is no relation demonstrated between sit-up performance and LBP when the feet are held. ${ }^{76}$ This action preferences hip flexor activity over abdominal participation.

Table 6 Model summary when five exercises entered individually

\section{Model fitting information}

\begin{tabular}{lllll}
\hline & \multicolumn{2}{l}{ Model fitting criteria } & Likelihood ratio tests & \\
\cline { 2 - 5 } Model & $\mathbf{- 2}$ log likelihood & $\chi^{2}$ & df & Sig. \\
\hline Intercept only & 429.927 & & 10 & \\
Final & 147.397 & 282.530 & 10 & 0.000 \\
\hline
\end{tabular}


Table 7 Parameter estimates when exercises entered individually

Parameter estimates

\begin{tabular}{|c|c|c|c|c|c|c|c|c|c|}
\hline \multirow[b]{2}{*}{ LBP* } & & \multirow[b]{2}{*}{ B } & \multirow[b]{2}{*}{ SE } & \multirow[b]{2}{*}{ Wald } & \multirow[b]{2}{*}{ df } & \multirow[b]{2}{*}{ Sig. } & \multirow[b]{2}{*}{$\operatorname{Exp}(B)$} & \multicolumn{2}{|c|}{$95 \% \mathrm{Cl}$ for $\operatorname{Exp}(\mathrm{B})$} \\
\hline & & & & & & & & Lower bound & Upper bound \\
\hline \multirow[t]{6}{*}{1.0} & Intercept & 3.320 & 0.520 & 40.719 & 1 & 0.000 & & & \\
\hline & EX1_EIL & -0.148 & 0.401 & 0.136 & 1 & 0.713 & 0.863 & 0.393 & 1.894 \\
\hline & EX2_situp & -1.326 & 0.284 & 21.827 & 1 & 0.000 & 0.266 & 0.152 & 0.463 \\
\hline & EX3_legext & -1.101 & 0.362 & 9.246 & 1 & 0.002 & 0.332 & 0.164 & 0.676 \\
\hline & EX4_squat & -0.959 & 0.298 & 10.337 & 1 & 0.001 & 0.383 & 0.214 & 0.688 \\
\hline & EX5_riseup & -1.540 & 0.413 & 13.929 & 1 & 0.000 & 0.214 & 0.096 & 0.481 \\
\hline \multirow[t]{6}{*}{2.0} & Intercept & 4.415 & 0.539 & 67.084 & 1 & 0.000 & & & \\
\hline & EX1_EIL & -1.050 & 0.440 & 5.698 & 1 & 0.017 & 0.350 & 0.148 & 0.829 \\
\hline & EX2_situp & -2.010 & 0.429 & 21.977 & 1 & 0.000 & 0.134 & 0.058 & 0.310 \\
\hline & EX3_legext & -1.666 & 0.432 & 14.854 & 1 & 0.000 & 0.189 & 0.081 & 0.441 \\
\hline & EX4_squat & -1.532 & 0.414 & 13.672 & 1 & 0.000 & 0.216 & 0.096 & 0.487 \\
\hline & EX5_riseup & -2.392 & 0.456 & 27.495 & 1 & 0.000 & 0.091 & 0.037 & 0.224 \\
\hline
\end{tabular}

${ }^{*}$ The reference category is: 0 .

LBP, low back pain.

Alternative actions that preference abdominal muscles, for example, partial curl-up, are more highly correlated to $\mathrm{LBP}^{77}{ }^{78}$ Our results provide guidance for future work that may contribute to a comprehensive screening, prevention and management approach to LBP.

\section{Study strengths and limitations}

The strengths of this study include the cross-sectional nature, the sample including both genders, diverse age groups and occupations but within one organisation and geographical region. This enabled continuity, and a degree of homogeneity in the otherwise varied sample, that strengthened the statistical findings with respect to general working populations. The sample had adequate power and representation of the constructs under consideration. The findings were statistically substantial in the effect size and the determined relationship between the physical tests and the presence of LBP. Causality, however, cannot be inferred from this study.

Other exercise tests may have similar utility. In choosing the exercise tests, we did not consider exercise dose and specificity for age and gender and these may be confounding factors. However, the statistical findings showed that the exercises chosen were relevant and that neither gender nor age influenced the results.

Other potential limitations were the use of a self-assessed diagnosis as participants were not physically examined and the reported LBP was their interpretation of the area 'above the buttocks to the region of waist'. Additionally, that participant self-reported gender was the only potential moderator or confounding variable included in the data. As noted above, gender itself was not a significant predictor in any analysis $(\mathrm{p}>0.80)$ and thus not included in analyses reported. We were unable to test for a significant interaction between gender and exercises (eg, EX_SUM) due to quasicomplete separation in the data. However, a trend appeared where the effects for males were slightly stronger. This might represent a direction for future research within larger samples or simply a sample artefact.

\section{Future research}

Determining the exercises indicative of LBP is imperative for diagnosis and setting discharge goals; the next step is to determine which intervention regimen/s could improve the ability to harmoniously perform and maintain the exercises in an optimised and scalable manner. This would require a prospective, longitudinal study with symptomatic/non-symptomatic LBP patients. Challenges in assessing efficacy are test standardisation plus gender variation in repetitions number or degree of movement as males are generally stronger and females more flexible. Furthermore, all measurements at baseline and follow-up must be accurate and sensitive. Consequently, a combination of physical tests and patient-reported outcomes are needed, where many currently preferred tools may not be sufficiently sensitive. ${ }^{27}$

Furthermore, this study had limited demographic variables. Consequently, future research may consider moderating factors aside from gender. Perhaps age is a differential consideration. However, the very strong analyses effects observed and that our lack of explicitly modelling these hidden variables would have biased the results towards the null, it is unlikely that unobserved variables are true confounders but might clarify and increase the sensitivity of some effects if modelled. As an observational study, however, it was not possible to indicate whether gradually training individuals to complete these five exercises could facilitate reductions in LBP. From the authors' clinical management protocol, it may be speculated that this appears possible. 


\section{CONCLUSION}

In a group of 422 predominantly male, Australian Council workers presenting in a mixed general working population, the ability to complete or not-complete five simple functional exercises showed a significant and meaningful clinical correlation with the presence or absence of LBP. Those able to perform more exercises were significantly less likely to report the presence of LBP, either sometimes or most of the time. Conversely, those unable to perform any or one exercise were more likely to report the presence of LBP most of the time. These findings could be useful for diagnostic purposes, and we hypothesised that training pain-free individuals to be able to complete the five exercises on a regular basis could facilitate prevention of LBP in a general working population. Furthermore, that a graded introduction of these or similar exercises as part of a supervised rehabilitation programme, for individuals recovering from an episode of LBP, may facilitate overall recovery and reduce recurrence. A prospective trial to investigate this hypothesis is to be initiated.

\section{Author affiliations}

${ }^{1}$ Research Department, Coolum Physiotherapy, Coolum Beach, Queensland, Australia

${ }^{2}$ Department of Ergonomics, University of Social Welfare and Rehabilitation Sciences, Tehran, Iran

${ }^{3}$ Human Movement, Independent Private Researcher, Placencia Village, Belize ${ }^{4}$ Department of Mathematical Sciences, Clemson University, Clemson, South Carolina, USA

${ }^{5}$ Department of Public Health Science, Clemson University, Clemson, South Carolina, USA

${ }^{6}$ School of Allied Health Sciences, Griffith University, Gold Coast, Queensland, Australia

${ }^{7}$ Mater Research, Mater Medical Research Institute, Brisbane, Queensland, Australia ${ }^{8}$ School of Health Professions, Zurich University of Applied Sciences, Winterthur, Switzerland

${ }^{9}$ Curtin Medical School, Curtin University, Perth, Western Australia, Australia

${ }^{10}$ UWA Medical School, University of Western Australia, Perth, Western Australia, Australia

Acknowledgements The authors wish to thank the participants and the management for their contributions and for enabling the programme and the recording of the findings to be completed and statistically analysed.

Contributors CPG provided the concept and design of the study, acquisition of participants and data, assisted data analysis and interpretation, drafting of manuscript and critical revising. HRM and JH provided drafting and critical revising of manuscript. J0 provided manuscript design, participants and data analysis and interpretation, drafting of manuscript and critical revising. LL provided data interpretation, drafting and critical revising of manuscript. MM provided concept and design input, assisted data analysis and interpretation, drafting of manuscript and critical revising.

Funding The authors have not declared a specific grant for this research from any funding agency in the public, commercial or not-for-profit sectors.

Competing interests None declared.

Patient consent Not required.

Ethics approval Ethics approval was from the Educational Committee of the Sunshine Coast Council with data collected under James Cook University, H1673, and the University of the Sunshine Coast HREC:S04/48/MC and HREC:08/10.

Provenance and peer review Not commissioned; externally peer reviewed.

Data sharing statement Extra data can be accessed via the Dryad data repository at http://datadryad.org/ with the doi: 10.5061/dryad.9g8q52g.
Open access This is an open access article distributed in accordance with the Creative Commons Attribution Non Commercial (CC BY-NC 4.0) license, which permits others to distribute, remix, adapt, build upon this work non-commercially, and license their derivative works on different terms, provided the original work is properly cited, appropriate credit is given, any changes made indicated, and the use is non-commercial. See: http://creativecommons.org/licenses/by-nc/4.0/.

\section{REFERENCES}

1. Deyo RA, Weinstein JN. Low back pain. N Engl J Med Overseas Ed 2001;344:363-70.

2. Balagué $F$, Mannion AF, Pellisé F, et al. Non-specific low back pain. Lancet 2012;379:482-91.

3. Buchbinder R, van Tulder M, Öberg B, et al. Low back pain: a call for action. Lancet 2018;391:2384-8.

4. GBD 2016 Disease and Injury Incidence and Prevalence Collaborators. Global, regional, and national incidence, prevalence, and years lived with disability for 328 diseases and injuries for 195 countries, 1990-2016: a systematic analysis for the Global Burden of Disease Study 2016. Lancet 2017;390:1211-59.

5. Murray CJL, Vos T, Lozano R, et al. Disability-adjusted life years (DALYs) for 291 diseases and injuries in 21 regions, 1990-2010: a systematic analysis for the Global Burden of Disease Study 2010. Lancet 2012;380:2197-223.

6. Hartvigsen J, Hancock MJ, Kongsted A, et al. What low back pain is and why we need to pay attention. Lancet 2018;391:2356-67.

7. Machado GC, Ferreira PH, Maher CG, et al. Transient physical and psychosocial activities increase the risk of nonpersistent and persistent low back pain: a case-crossover study with 12 months follow-up. The Spine Journal 2016;16:1445-52.

8. Deyo RA. Treatments for back pain: can we get past trivial effects? Ann Intern Med 2004;141:957-8.

9. Kohns DJ, Haig AJ, Uren B, et al. Clinical predictors of the medical interventions provided to patients with low back pain in the emergency department. J Back Musculoskelet Rehabil 2018;31:197-204.

10. Dubois J-D, Cantin V, Piché M, et al. Physiological and psychological predictors of short-term disability in workers with a history of low back pain: a longitudinal study. PLoS One 2016;11:e0165478.

11. Foster NE, Anema JR, Cherkin D, et al. Prevention and treatment of low back pain: evidence, challenges, and promising directions. Lancet 2018;391:2368-83.

12. Steffens $D$, Ferreira ML, Latimer $\mathrm{J}$, et al. What triggers an episode of acute low back pain? A case-crossover study. Arthritis Care Res 2015;67:403-10.

13. Gabel CP, Burkett B, Melloh M. The shortened örebro musculoskeletal screening questionnaire: evaluation in a workinjured population. Man Ther 2013;18:378-85.

14. O'Sullivan P. Diagnosis and classification of chronic low back pain disorders: maladaptive movement and motor control impairments as underlying mechanism. Man Ther 2005;10:242-55.

15. Pind R. Testing a New 10-Item Scale (Pind's LBP Test) for prediction of sick leave lasting more than three days or more than two weeks after a general practitioner visit for acute low back pain. Spine 2014;39:E581-E586.

16. Verbunt JA, Seelen HA, Vlaeyen JW, et al. Disuse and deconditioning in chronic low back pain: concepts and hypotheses on contributing mechanisms. Eur J Pain 2003;7:9-21.

17. Johnsen LG, Hellum C, Nygaard OP, et al. Comparison of the SF6D the EQ5D, and the oswestry disability index in patients with chronic low back pain and degenerative disc disease. BMC Musculoskelet Disord 2013;14:148.

18. Melloh M, Aebli N, Elfering A, et al. Development of a screening tool predicting the transition from acute to chronic low back pain for patients in a GP setting: protocol of a multinational prospective cohort study. BMC Musculoskelet Disord 2008;9:167.

19. Williams CM, Hancock MJ, Maher CG, et al. Predicting rapid recovery from acute low back pain based on the intensity, duration and history of pain: A validation study. European Journal of Pain 2014;18:1182-9.

20. Hancock MJ, Maher CM, Petocz P, et al. Risk factors for a recurrence of low back pain. Spine J 2015;15:2360-8.

21. E F Graves L, C Murphy R, Shepherd SO, et al. Evaluation of sitstand workstations in an office setting: a randomised controlled trial. BMC Public Health 2015;15:1145.

22. de Cássia Pereira Fernandes R, Pataro SMS, de Carvalho RB, et al. The concurrence of musculoskeletal pain and associated 
work-related factors: a cross sectional study. BMC Public Health 2016;16:628.

23. Maus T. Imaging the back pain patient. Phys Med Rehabil Clin N Am 2010;21:725-66.

24. de Schepper EIT, Koes BW, Veldhuizen EFH, et al. Prevalence of spinal pathology in patients presenting for lumbar MRI as referred from general practice. Fam Pract 2016;33:51-6.

25. Khan I, Hargunani R, Saifuddin A. The lumbar high-intensity zone: 20 years on. Clin Radiol 2014;69:551-8

26. van Abbema R, Lakke SE, Reneman MF, et al. Factors associated with functional capacity test results in patients with non-specific chronic low back pain: a systematic review. J Occup Rehabil 2011;21:455-73.

27. Gabel CP, Cuesta-Vargas A, Qian M, et al. The Oswestry Disability Index, confirmatory factor analysis in a sample of 35,263 verifies a one-factor structure but practicality issues remain. European Spine Journal 2017;26:2007-13.

28. de Schepper EIT, Koes BW, Oei EHG, et al. The added prognostic value of MRI findings for recovery in patients with low back pain in primary care: a 1-year follow-up cohort study. European Spine Journal 2016;25:1234-41.

29. Melloh M, Elfering A, Käser A, et al. What is the best time point to identify patients at risk of developing persistent low back pain? $J$ Back Musculoskelet Rehabil 2015;28:267-76.

30. Gabel CP, Osborne J, Burkett B, et al. Letters. TO THE EDITOR: Linton SJ, Nicholas M, MacDonald S. Development of a short form of the Örebro Musculoskeletal Pain Screening Questionnaire. Spine (Phila Pa 1976) 2011;36:1891-5. Spine 2015;40:E913.

31. Sterud T, Tynes T. Work-related psychosocial and mechanical risk factors for low back pain: a 3-year follow-up study of the general working population in Norway. Occup Environ Med 2013;70:296-302

32. Robinson HS, Dagfinrud H. Reliability and screening ability of the StarT Back screening tool in patients with low back pain in physiotherapy practice, a cohort study. BMC Musculoskelet Disord 2017;18:232.

33. Beneciuk JM, Bishop MD, Fritz JM, et al. The STarT back screening tool and individual psychological measures: evaluation of prognostic capabilities for low back pain clinical outcomes in outpatient physical therapy settings. Phys Ther 2013;93:321-33.

34. Mitchell T, O'Sullivan PB, Burnett A, et al. Identification of modifiable personal factors that predict new-onset low back pain: a prospective study of female nursing students. Clin J Pain 2010;26:275-83.

35. Hoffman J, Gabel CP. The origins of Western mind-body exercise methods. Physical Therapy Reviews 2015;20:315-24.

36. Hoffman J, Gabel P. Expanding Panjabi's stability model to express movement: A theoretical model. Med Hypotheses 2013;80:692-7.

37. Micheo W, Baerga L, Miranda G. Basic principles regarding strength, flexibility, and stability exercises. Pm R 2012;4:805-11.

38. Grönblad M, Järvinen E, Hurri $\mathrm{H}$, et al. Relationship of the Pain Disability Index (PDI) and the Oswestry Disability Questionnaire (ODQ) with three dynamic physical tests in a group of patients with chronic low-back and leg pain. Clin J Pain 1994;10:197-203.

39. Broonen J-P, Marty M, Legout V, et al. Is volition the missing link in the management of low back pain? Joint Bone Spine 2011;78:364-7.

40. Henchoz Y, Kai-Lik So A. Exercise and nonspecific low back pain: a literature review. Joint Bone Spine 2008;75:533-9.

41. Ng JK, Richardson CA, Kippers V, et al. Relationship between muscle fiber composition and functional capacity of back muscles in healthy subjects and patients with back pain. J Orthop Sports Phys Ther 1998;27:389-402.

42. Goubert D, Oosterwijck JV, Meeus M, et al. Structural changes of lumbar muscles in non-specific low back pain: a systematic review. Pain Physician 2016;19:E985-E1000.

43. Mannion AF, Taimela S, Müntener M, et al. Active therapy for chronic low back pain part 1. Effects on back muscle activation, fatigability, and strength. Spine 2001;26:897-908.

44. Melloh M, Elfering A, Käser A, et al. Depression impacts the course of recovery in patients with acute low-back pain. Behav Med 2013;39:80-9.

45. Elfering A, Mannion AF. Epidemiology and risk factors of spinal disorders. In: Boos N, Aebi M, eds. Spinal disorders - fundamentals of diagnosis and treatment. Berlin Heidelberg, New York: Springer, 2008:153-73.

46. Marich AV, Hwang C-T, Salsich GB, et al. Consistency of a lumbar movement pattern across functional activities in people with low back pain. Clin Biomech 2017;44:45-51.

47. Grönblad M, Hurri H, Kouri JP. Relationships between spinal mobility, physical performance tests, pain intensity and disability assessments in chronic low back pain patients. Scand J Rehabil Med 1997;29:17-24.

48. Riihimäki H, Tola S, Videman $\mathrm{T}$, et al. Low-back pain and occupation. A cross-sectional questionnaire study of men in machine operating, dynamic physical work, and sedentary work. Spine 1989;14:204-9.

49. Lao J, Hansen A, Nitschke M, et al. Working smart: an exploration of council workers' experiences and perceptions of heat in adelaide, South Australia. Saf Sci 2016;82:228-35.

50. Trask C, Bath B, Johnson PW, et al. Risk factors for low back disorders in saskatchewan farmers: fieled-based exposure assessment to build a foundation for epidemiological studies. JMIR Res Protoc 2016;5:e111.

51. Coenen P, Kingma I, Boot CRL, et al. Cumulative mechanical lowback load at work is a determinant of low-back pain. Occup Environ Med 2014;71:332-7.

52. Panjabi MM. Clinical spinal instability and low back pain. Journal of Electromyography and Kinesiology 2003;13:371-9.

53. Johnson CD, Whitehead PN, Pletcher ER, et al. The relationship of core strength and activation and performance on three functional movement screens. J Strength Cond Res 2018;32:1166-73.

54. Zannotti CM, Bohannon RW, Tiberio D, et al. Kinematics of the double-leg-lowering test for abdominal muscle strength. Journal of Orthopaedic \& Sports Physical Therapy 2002;32:432-6.

55. Sullivan MS, Shoaf LD, Riddle DL. The relationship of lumbar flexion to disability in patients with low back pain. Phys Ther 2000;80:240-50.

56. Carlsson H, Rasmussen-Barr E. Clinical screening tests for assessing movement control in non-specific low-back pain. A systematic review of intra- and inter-observer reliability studies. Man Ther 2013;18:103-10.

57. Kessler RC, Adler L, Ames M, et al. The world health organization adult ADHD self-report scale (ASRS): a short screening scale for use in the general population. Psychol Med 1999;35:245-56.

58. Albarracin D, Johnson BT, Zanna MP. The handbook of attitudes. Hillsdale, NJ: Erlbaum, 2005.

59. Gabel CP, Michener LA, Melloh M, et al. Modification of the upper limb functional index to a three-point response improves clinimetric properties. Journal of Hand Therapy 2010;23:41-52.

60. Krosnick JA. The handbook of questionnaire design. New York: Oxford University Press, 1991.

61. Jacoby J, Matell MS. Three-point likert scales are good enough. $J$ Marketng Res 1971;8:495-500.

62. Newcombe RG. Estimating the difference between differences: measurement of additive scale interaction for proportions. Stat Med 2001;20:2885-93.

63. Osborne JW. Regression and linear modeling: Best practices and modern methods. Thousand Oaks, CA: SAGE Publishing, 2017.

64. Cho NH, Jung YO, Lim SH, et al. The prevalence and risk factors of low back pain in rural community residents of Korea. Spine 2012;37:2001-10.

65. Halliday $\mathrm{MH}$, Ferreira $\mathrm{PH}$, Hancock $\mathrm{MJ}$, et al. A randomised controlled trial protocol comparing McKenzie Therapy and motor control exercises on trunk muscle recruitment in people with chronic low back pain and directional. Physiotherapy 2015;101:232-8.

66. Chun SW, Lim CY, Kim K, et al. The relationships between low back pain and lumbar lordosis: a systematic review and meta-analysis. Spine J 2017;17:1180-91.

67. May S, Aina A. Centralization and directional preference: A systematic review. Man Ther 2012;17:497-506.

68. Bauer CM, Rast FM, Ernst MJ, et al. The effect of muscle fatigue and low back pain on lumbar movement variability and complexity. Journal of Electromyography and Kinesiology 2017:33:94-102.

69. Andersen K, Baardsen R, Dalen I, et al. Impact of exercise programs among helicopter pilots with transient LBP. BMC Musculoskelet Disord 2017;18:269.

70. van Middelkoop M, Rubinstein SM, Verhagen AP, et al. Exercise therapy for chronic nonspecific low-back pain. Best Pract Res Clin Rheumatol 2010;24:193-204.

71. Lin C-WC, Haas M, Maher CG, et al. Cost-effectiveness of guideline-endorsed treatments for low back pain: a systematic review. European Spine Journal 2011;20:1024-38.

72. McGill SM, Grenier S, Kavcic N, et al. Coordination of muscle activity to assure stability of the lumbar spine. J Electromyogr Kinesiol 2003;13:353-9.

73. Ikeda DM, McGill SM. Can altering motions, postures, and loads provide immediate low back pain relief: a study of 4 cases investigating spine load, posture, and stability. Spine 2012;37:E1469-75. 
74. Bell JA, Burnett A. Exercise for the primary, secondary and tertiary prevention of low back pain in the workplace: a systematic review. $J$ Occup Rehabil 2009;19:8-24.

75. Myrtos CD. Low Back Disorders. Evidence-Based Prevention and Rehabilitation. J Canad Chiro Assoc 2012;56:76

76. Jackson AW, Morrow JR, Brill PA, et al. Relations of sit-up and sitand-reach tests to low back pain in Adults. J Orthop Sports Phys Ther 1998;27:22-6.

77. Parfrey KC, Docherty D, Workman RC, et al. The effects of different sit- and curl-up positions on activation of abdominal and hip flexor musculature. Appl Physiol Nutr Metab 2008;33:888-95.

78. Moya-Ramón M, Juan-Recio C, Lopez-Plaza D, et al. Dynamic trunk muscle endurance profile in adolescents aged 14-18: Normative values for age and gender differences. J Back Musculoskelet Rehabil 2018;31:155-162.

79. Panjabi MM, Oxland TR, Yamamoto I, et al. Mechanical behavior of the human lumbar and lumbosacral spine as shown by threedimensional load-displacement curves. The Journal of Bone \& Joint Surgery 1994;76:413-24.

80. Steele J, Bruce-Low S, Smith D, et al. A randomized controlled trial of limited range of motion lumbar extension exercise in chronic low back pain. Spine 2013;38:1245-52.

81. Mazzone B, Wood R, Gombatto S. Spine kinematics during prone extension in people with and without low back pain and among classification-specific low back pain subgroups. J Orthop Sports Phys Ther 2016;46:571-9.

82. Apeldoorn AT, van Helvoirt $\mathrm{H}$, Meihuizen $\mathrm{H}$, et al. The Influence of Centralization and Directional Preference on Spinal Control in Patients With Nonspecific Low Back Pain. J Orthop Sports Phys Ther 2016;46:258-69.

83. McKenzie R, May S. The lumbar spine: mechanical diagnosis and therapy, Volume 1. New Zealand: Waikanae, New Zealand Spinal Publications, 2003.

84. Scannell JP, McGill SM. Disc prolapse: evidence of reversal with repeated extension. Spine 2009;34:344-50.

85. Youdas JW, Suman VJ, Garrett TR. Reliability of measurements of lumbar spine sagittal mobility obtained with the flexible curve. Journal of Orthopaedic \& Sports Physical Therapy 1995;21:13-20.

86. Lehman GJ, Story S, Mabee R. Influence of static lumbar flexion on the trunk muscles' response to sudden arm movements. Chiropr Osteopat 2005;13:23

87. Abboud J, Lardon A, Boivin F, et al. Effects of muscle fatigue, creep, and musculoskeletal pain on neuromuscular responses to unexpected perturbation of the trunk: a systematic review. Front Hum Neurosci 2017;10:667.

88. Fry DK, Huang M, Rodda BJ. Core muscle strength and endurance measures in ambulatory persons with multiple sclerosis. Int $J$ Rehabil Res 2015;38:206-12.
89. Arokoski JP, Valta T, Kankaanpää M, et al. Activation of lumbar paraspinal and abdominal muscles during therapeutic exercises in chronic low back pain patients. Arch Phys Med Rehabil 2004;85:823-32.

90. Shields RK, Heiss DG. An electromyographic comparison of abdominal muscle synergies during curl and double straight leg lowering exercises with control of the pelvic position. Spine 1997;22:1873-9.

91. Byström MG, Rasmussen-Barr E, Grooten WJA. Motor control exercises reduces pain and disability in chronic and recurrent low back pain. Spine 2013;38:E350-E358.

92. Enoch F, Kjaer P, Elkjaer A, et al. Inter-examiner reproducibility of tests for lumbar motor control. BMC Musculoskelet Disord 2011;12:114.

93. Linek $\mathrm{P}$, Saulicz $\mathrm{E}$, Wolny $\mathrm{T}$, et al. Intra-rater reliability of b-mode ultrasound imaging of the abdominal muscles in healthy adolescents during the active straight leg raise test. $P m R$ 2015;7:53-9.

94. Schoenfeld BJ. Squatting kinematics and kinetics and their application to exercise performance. J Strength Cond Res 2010;24:3497-506.

95. Clark DR, Lambert MI, Hunter AM. Muscle activation in the loaded free barbell squat. J Strength Cond Res 2012;26:1169-78.

96. Hsiang SM, Brogmus GE, Courtney TK, et al. Low back pain (LBP) and lifting technique - A review. Int J Ind Ergon 1997;19:59-74.

97. Welch N, Moran K, Antony J, et al. The effects of a free-weightbased resistance training intervention on pain, squat biomechanics and MRI-defined lumbar fat infiltration and functional crosssectional area in those with chronic low back. BMJ Open Sport Exerc Med 2015;1:e000050.

98. Edwards S, Liberatore M. Reliability of a squat movement competency screen in individuals with a previous knee injury. $J$ Sport Rehabil 2018;5:1-26.

99. Moran RW, Schneiders AG, Major KM, et al. How reliable are Functional Movement Screening scores? A systematic review of rater reliability. Br J Sports Med 2016;50:527-36.

100. Bonazza NA, Smuin D, Onks CA, et al. Reliability, validity, and injury predictive value of the functional movement screen: a systematic review and meta-analysis. Am J Sports Med 2017;45:725-32.

101. Bazrgari B, Shirazi-Adl A, Arjmand N. Analysis of squat and stoop dynamic liftings: muscle forces and internal spinal loads. European Spine Journal 2007;16:687-99.

102. Rahmani A, Viale F, Dalleau G, et al. Force/velocity and power/ velocity relationships in squat exercise. Eur J Appl Physiol 2001;84:227-32. 